\title{
One in every four women living with HIV had unmet need for family planning in Gondar city, Northwest Ethiopia: Cross-sectional study
}

\section{Mihret Dejen Kassie}

University of Gondar College of Medicine and Health Sciences

\section{Yohannes Ayanaw Habitu}

University of Gondar College of Medicine and Health Sciences

Simegnew Handebo ( $\nabla$ hsimegnew@yahoo.com )

University of Gondar College of Medicine and Health Sciences

\section{Research article}

Keywords: Unmet need for Family planning, HIV-positive women, ART, Ethiopia.

Posted Date: September 5th, 2019

DOl: https://doi.org/10.21203/rs.2.13910/v1

License: (c) (i) This work is licensed under a Creative Commons Attribution 4.0 International License.

Read Full License 


\section{Abstract}

Background All women, including those living with HIV, have the right to choose the timing, spacing, and number of their births and need access to family planning services.Objective To assess the prevalence and factors associated with unmet need for family planning among women attending Anti retro viral Therapy (ART).Methods Facility-based cross sectional study was conducted from March, to April, 2018 in Gondar town, Ethiopia. Systematic random sampling technique was used to recruit respondents. A total of 441 reproductive age women on ART were included in the study. The data were collected using a pretested structured questionnaire. Bivariate and backward multivariable logistic regression model was fitted to identify factors associated with unmet need for family planning. Adjusted Odds Ratio (AOR) and $95 \%$ confidence interval was computed.Results The prevalence of unmet need for family planning was 24.5\% (95\% Cl: 20.4-28.8). Rural residence (AOR: $2.11,95 \% \mathrm{Cl}(1.02,4.36)$ ), women aged 20-29 years (AOR: $0.29,95 \% \mathrm{Cl}(0.09,0.93)$ ), 30-34 years (AOR: $0.30,95 \% \mathrm{Cl}(0.10,0.92)), 35-39$ years (AOR: $0.14,95 \%$ $\mathrm{Cl}(0.04,0.45)$ ), and above 40 years (AOR: $0.08,95 \% \mathrm{Cl}(0.02,0.38)$ ), have more than three children (AOR: $0.12,95 \% \mathrm{Cl}(0.04,0.36)$ ), intention to have more children (AOR: $0.08,95 \% \mathrm{Cl}(0.03,0.23)$ ), who did not disclose their sero-status to partner (AOR: $0.39,95 \% \mathrm{Cl}(0.19,0.81)$ ), having no experience of contraception use (AOR: $0.44,95 \% \mathrm{Cl}(0.21,0.92)$ ) were significantly associated with unmet need for family planning.Conclusion One in every four women living with HIV had unmet need for family planning. Rural residence, age of the women, having $>3$ children, intention to have more children, not disclosing sero-status to partner, and having no experience of contraception use were significantly associated with unmet need for family planning.

\section{Background}

Globally, an estimated 36.7 million persons are living with HIV, including estimated 1.8 million new infections in 2016. Of which 51\% (17.8 million) are women aged 15 and older. Sub-Saharan Africa remains the most seriously affected region in the world [1]. Similarly, in Ethiopia an estimated 722,248 persons are living with HIV, women of reproductive age account for nearly $57 \%$ percent of all cases [2].

Family planning plays a vital part in preventing transmission of HIV. It is the more cost effective intervention for preventing mother to child transmissions (PMTCT) of human immunodeficiency virus (HIV), which is by far the main cause of HIV infection in children below the age of 15 years. In addition, family planning also prevents maternal morbidity and mortality that is caused by unintended pregnancy [3-8]. Unmet need for family planning is a more robust indicator of the contraceptive utilization gaps [9].Unmet need is the percentage of women who are married or in unions, fecund and sexually active, who wants to stop childbearing or delay their next birth by at least two years, but are not using any method of contraception, either modern or traditional [10-12].

The 2016 Ethiopian Demographic and Health Survey (EDHS) reported $58 \%$ of currently married women age $15-49$ have a demand for family planning; $35 \%$ want to space births, and $24 \%$ want to limit births. However, $22 \%$ of them have an unmet need for family planning: $13 \%$ to space or $9 \%$ limit births but are 
not currently using contraception. This unmet need for family planning in the country declined nearly by half over time, from $37 \%$ in 2000 to $22 \%$ in 2016 [12].

Empirical evidences have demonstrated that women who are living with HIV have a lower fertility desire and better use of contraceptives as compared to their HIV negative counterparts [13, 14]. Preventing unintended pregnancies among women living with HIV is one of the four comprehensive approaches that the World Health Organization (WHO) promotes to prevent the transmission of HIV from mother to baby [15].

Current evidences indicates that the unmet need for family planning among women living with HIV remains high in Sub-Saharan Africa. Studies done in different African countries showed that unmet need for family planning was range from Malawi $21.9 \%$ to $49 \%$ in Nigeria [16-22]. With regard to Ethiopia studies done in different part of the country showed that the unmet need for family planning among HIV positive women on ART ranges $15.4 \%$ in Nekemt, to $24.6 \%$ in south Gondar and north wollo [23-25].

Studies conducted across multiple international contexts confirm the unique nature of FP needs for HIV positive women. This particular nature of the unmet need for family planning among HIV positive women is different for each individual woman. Besides, the factors associated with this unmet need also vary across different contexts in the world. So, this study was conducted to determine the prevalence and associated factors of unmet need for family planning among HIV positive women in Gondar town, Northwest Ethiopia.

\section{Methods}

\section{Study design and setting}

Facility-based cross-sectional study was conducted from March, to April, 2018 at Gondar town, which is located at $727 \mathrm{~km}$ away from Addis Ababa. Gondar town is one of the administrative towns in Amhara region. One specialized hospital and eight health centers are providing health services in the town. There are 9,122 ART users in the town. (Gondar town health bureau, 2016 annual report, unpublished).

\section{Study participant and sampling}

All of reproductive age (15-49 years) women living with HIV and started ART, and had a follow up at ART clinics during the data collection period were included in the study. The sample size was determined by using the estimation of single population proportion formula with an assumption of $95 \%$ confidence interval, $4 \%$ margin of error, and $24.6 \%$ of expected proportion of unmet need for family planning [25]. After considering the correction formula and compensation for the non-response rate the final sample size was 441 .

In the town five health centers were providing ART services. The total sample size was proportionally allocated to each health center based on the number of reproductive age women who were receiving ART 
on each health center. Systematic random sampling method was employed to select participants in each of the facilities by using client flow as sampling frame.

\section{Data collection tools and procedures}

A structured and pretested interviewer administered questionnaire composed of socio-demographic characteristics, clinical, reproductive, communication and health facility factors was used for collecting the data. First, the questionnaire was prepared in English and translated into Amharic (the local language), and then translated back to English to check the consistency. Five BSC nurses, who are working in ART clinics, data collectors and two health officer supervisors were involved in the data collection process. Onsite training was given for data collectors and supervisors on the objective of the research, on the procedure of data collection and ethical issues. The principal investigator and supervisor made day to day supervision during the data collection.

\section{Operational definition}

\section{Unmet need for family planning}

Proportion of women with HIV who are not pregnant and not postpartum amenorrheic and are considered fecund and want to postpone their next birth for 2 or more years or stop childbearing altogether but are not using a contraceptive method, or have a mistimed or unwanted current pregnancy, or are postpartum amenorrheic and their last birth in the last 2 years was mistimed or unwanted Percentage of fertile, sexually active women with HIV aged 15-49 who are not using contraception and do not wish to become pregnant at all (unmet need for limiting) or within the next two years (unmet need for spacing) [26].

\section{Data processing and analysis}

The collected data were entered, edited and cleaned using Epi info version 7 and analyzed using SPSS version 20. After bivariable analysis was done, variables with p-values of $<0.2$ were entered into a multivariable logistic regression model to identify factors associated with unmet need for family planning. Adjusted odds ratios (AOR) with 95\% confidence intervals ( $\mathrm{Cl}$ ) were computed and P-value $<0.05$ were considered statistically significant.

\section{Ethical consideration}

Ethical clearance was obtained from the Institutional Review Board of the University of Gondar Institute Of Public Health. Letter of permission to conduct the study was obtained from Gondar town health office and each health center administrators. Informed consent was obtained from each study participant. To ensure confidentiality names of the study participants were not recorded on the questionnaire and privacy was maintained during interview. In addition, the collected data was kept locked in file cabinet.

\section{Results}




\section{Socio demographic characteristics}

A total of 441 women in reproductive age on ART were enrolled in the study making the response rate $100 \%$. The mean age of the participants were $33.59 \pm 5.31$ years. More than half of them, $256(58 \%)$ were an urban dwellers. Majority of them 404 (91.6\%) were orthodox Christians and 430(97.4\%) were Amhara in ethnicity. Two hundred forty seven $(56 \%)$ of the respondents were married. With regard to educational status 139 (31.5\%) were illiterate. One hundred forty four (32.7\%) of the women were housewives (Table 1).

\section{Communication characteristics of study participant}

Among the total 441 participants, $336(76.2 \%)$ knew sero-status of their partner and eighty seven (25.9\%) of their partner were sero-positive. One hundred eighty four (41.7\%) of the respondents disclose their serostatus for their partners. The main purpose, $253(57.4 \%)$ of disclosing were to support each other. Seventy two $(16.3 \%)$ of the respondents change their partner because of divorce which is, $44(61.1 \%)$. Two hundred eighty five (64.6\%) of the participant believed that, as if contraceptive use might exacerbate HIV disease progression. Three hundred ninety three $(89.1 \%)$ of the women said that, family planning service charge would affect their contraceptive utilization. Two hundred eighty six $(72.8 \%)$ of respondents were in support of their spouse on family planning service utilization.

\section{Reproductive and sexual characteristics}

Two hundred eighty four (64.4\%) had less than five children and 238 (54\%) had desire for more children. Additionally, 302 (68.5\%) of women had history of sexual intercourse in the last six months and $260(59 \%)$ had single sexual partner. Of the study participants $299(67.8 \%)$ of them had information on dual family planning methods and only $46(19.1 \%)$ of them consistently use condom when they experience sexual intercourse (Table 2).

\section{Health facility and clinical factors}

Currently 108 (24.5\%) of respondents did not use any contraceptive methods. Three hundred forty $(77.1 \%)$ had ever used modern contraceptives in their life. Injectable was the most preferred method. However, $341(77.3 \%)$ of women had fear of side effects. Sixty two (14.1\%) had ever acquire STIs in their life and fifty six (12.7\%) seek and got treatment out of the total respondents. Even though, 311 (70.5\%) of the family planning was integrated with ART service, 236 (53.5\%) of the patient on ART were less than six months duration. About $3 / 4^{\text {th }}$ of the respondents, $273(80.0 \%)$ respond that, contraceptive use exacerbates HIV disease progression. But, 358 (81.2\%) said that distance of their residence could not influence on their contraceptive use (Table 3).

\section{Prevalence of unmet need for family planning}

Prevalence of unmet need for family planning was $24.5 \%$ with $95 \% \mathrm{Cl}(20.4-28.8)$ with $15.4 \%$ for spacing and $9.1 \%$ for limiting. The unmet need was composed of pregnant/amenorrheic women and non- 
pregnant/non amenorrheic women, which was mistimed pregnancy/birth, $12(2.72 \%)$, unwanted pregnancy/birth, 16(3.62\%) and those who planned their future pregnancy, want later, 56(12.7\%) and want no more, 24(5.4\%) There were no women who wanted pregnancy soon. Twenty eight (6.4\%) were unplanned pregnancy and $80(18.1 \%)$ were fecund, but were not pregnant and were not have a desire to be pregnant within 2 years.

\section{Factors associated with unmet need for family planning.}

In the multivariable logistic regression analysis, residence, age of the women, number of alive children, intention to have more children and ever use of contraception had a statistically significant association with unmet need for family planning.

Women who live in rural place had 2.11 times higher odds of having unmet need for family planning than those who live in urban (AOR: $2.11,95 \% \mathrm{Cl}(1.02,4.36)$ ). The odds of unmet need for family planning among women in the age group $20-29$ was $71 \%$ less than those in the age group of $15-24$. (AOR: 0.29 , $95 \% \mathrm{Cl}(0.09,0.93))$. The odds of unmet need for family planning among women in the age group 30-34 was $70 \%$ less than those in the age group of $15-24$. (AOR: $0.30,95 \% \mathrm{Cl}(0.10,0.92)$ ). The odds of unmet need for family planning among women in the age group 35-39 was $86 \%$ less than those in the age group of $15-24$. (AOR: $0.14,95 \% \mathrm{Cl}(0.04,0.45)$ ). The odds of unmet need for family planning among women in the age group above 40 was $92 \%$ less than those in the age group of $15-24$. (AOR: $0.08,95 \% \mathrm{Cl}(0.02$, 0.38)).The odds of unmet need for family planning among women who have more than three children was $88 \%$ less than those who have three and less children (AOR: $0.12,95 \% \mathrm{Cl}(0.04,0.36)$ ). The odds of unmet need for family planning among women who do not intend to have more children was $92 \%$ less than those who intent to have more children (AOR: $0.08,95 \% \mathrm{Cl}(0.03,0.23)$ ). The odds of unmet need for family planning among women who do not disclose their sero-status to their partner was $61 \%$ less than those who disclose their sero-status (AOR: $0.39,95 \% \mathrm{Cl}(0.19,0.81)$ ). The odds of unmet need for family planning among women who do not ever use contraception was $56 \%$ less than those who ever used contraception (AOR: $0.44,95 \% \mathrm{Cl}(0.21,0.92)$ ) (Table 4).

\section{Discussion}

This study aimed to measure the magnitude of unmet need for family planning and its associated factors among HIV positive women on ART. According to this study's finding, the prevalence of unmet need for family planning was $24.5 \%$ (95\% Cl: 20.4-28.8). This finding was in line with studies done in, North Tanzania [17], Ghana [18], South Gondar and North Wollo [25]. This may be due to the similarity of study participant characteristics and Ethiopian government is striving to address unmet need for family planning.

However, the finding was lower than the studies done in Nsambya (45.1\%) and Mulago at $30.9 \%$ clinics in Uganda, Kampala [20], Nairobi Kenya 33.6\% [19] and Nigeria 49\% [22]. This discrepancy might be due to the difference in health service provision, initiation and scaling up of health extension workers and consistent implication of sustainable development goals, investment focus on maternal health by the 
government and awareness creation towards health through health development army were some of the inputs for the lower record of our findings [5].

This finding was higher than the findings in Nekemt 15.4\% [23] and Hawasa 19.1\% [24]. The possible reasons may be due to behavioral difference, difference in health service provision access and utilization.

In this study, residence of HIV positive women was significantly associated with unmet need for family planning. Rural women on ART have almost 2 times more experience of unmet need for family planning as compared to those who live in urban. This result is supported by Ethiopian health and demography survey finding for general population [12]. This is due difficulties to difference in the distribution of health facilities, and access to roads and public transport $[27,28]$.

Unmet need for family planning was also lower among women in the age group of 20-29, 30-34, 35-39 and above 40 years old compared to age group 15-24. This finding is similar with a study done in Hawassa, South Ethiopia [24]. In addition this finding is similar with survey result in general population in Ethiopia; in which unmet need for family planning is significantly higher among women of younger age groups as compared with old aged women [29]. This might be due to raised awareness on family planning as a result of expanded of school based family planning programmes. This finding contradicted with a study done Nsambya district, Uganda; where older women more likely have unmet need for family planning [20]. Lower perception of the risk of pregnancy, and access with youth friendly services, school health and integrated services result such differences $[29,30]$.

Women who already had more than three children have $88 \%$ lower risk to unmet need for family planning than those who have three and less children. The possible explanation may be, the more the number of alive children the woman had, the lower the chance of having unmet need for family planning methods. Similarly, in this study women who do not have an intention to have more children have $92 \%$ lower unmet need for family planning. This finding was inconsistent with studies done in Kenya, Malawi and Nigeria $[19,20,22]$. Multiparous women will have more need of contraception to limit the number of children they have compared to women with no or few children. The difference may be due to lower perception of the risk of pregnancy as the women aged, have no intention to be pregnant and had more children.

In this study women who do not disclose their HIV sero-status for their partner have $61 \%$ lower risk of unmet need for family planning than those who did. This finding specify disclosure of their status to their partner is a key to take informed decisions positive health outcomes. All women should be encouraged to do so as much as possible [18].

This study finding also revealed that women who previously have no experience contraceptive use were $56 \%$ less likely to have unmet need for family planning. This study finding is different from study done in Nigeria [22]. As women had previous experience of using a method were more likely need to use in the future. But, due to health service accessibility issues they may have unmet need for family planning. 
This study has some limitations. The primary limitation of the study was the use of cross-sectional data, which rule out the analysis of causal association. On the other there was a risk of social desirability bias whereby women living with HIV may over-report their contraceptive use (condom use). The questionnaire was administered by nurses who were working in ART clinics to minimize this bias.

\section{Conclusion}

The Prevalence of unmet need for family planning among HIV positive women was high. Place of residence, age of the women, number of alive children, intention to have more children and ever use of contraception were the main factors associated with unmet need for family planning. So, continuous awareness raising activities on family planning for women on ART services is required. In addition professionals should give due emphasis for the rural and younger age women.

\section{Abbreviations}

ART: Anti Retro Viral Treatment, AIDS: Acquired Immuno Deficiency Syndrome, ANC: Ante Natal Care, Cl: Confidence Interval, CSA: Central Statistics Agency, ETB: Ethiopian Birr, HAART: Highly Active Anti Retro Viral Therapy, HIV: Human Immuno Deficiency Virus, OR: Odds Ratio, SD: Standard Deviation, SPSS: Statistical Package for Social Science, UNAIDS: United Nations Agency for International Developments, WHO: World Health Organization,

\section{Declarations}

\section{Ethics and consent}

Ethical clearance was obtained from the Institutional Review Board of the University of Gondar Institute Of Public Health. Letter of permission to conduct the study was obtained from Gondar town health office and each health center administrators. Informed consent was obtained from each study participant. To ensure confidentiality names of the study participants were not recorded on the questionnaire and privacy was maintained during interview. In addition, the collected data was kept locked in file cabinet.

\section{Consent for publication}

Not applicable

\section{Availability of data and materials}

We confirmed that all data underlying the findings would be fully available without restriction if the manuscript is published.

\section{Competing interests}

The authors declare that they have no conflict of interest 


\section{Funding}

The authors received no specific funding for this work

\section{Authors' contribution}

Conceived and designed the study: MDK YAH SHB. Performed the study: MDK YAH SHB. Analyzed the data: MDK YAH SHB. Contributed materials/analysis tools: MDK YAH SHB. Wrote the Manuscript: MDK YAH SHB. All authors read and approved the final manuscript.

\section{Acknowledgements}

We would like to thank the study participants, data collectors and supervisors.

\section{References}

1. UNAIDS special analysis, 2017. 2017 Global AIDS Monitoring. UNAIDS 2017 estimates. 2017 National Commitments and Policy Instrument. European Centers for Disease Control and Prevention Continuum of HIV care 2017 progress report.

2. Ethiopian public health institute, HIV Related Estimates and Projections for Ethiopia; Addis Ababa, March 2017

3. Speidel, J.J., Harper, C.C., and Shields, W.C. (2008). The potential of long-acting reversible contraception to decrease unintended pregnancy. Contraception 78:197-200.

4. Halperin DT, Stover J, Reynolds HW. Benefits and costs of expanding access to family planning programs to women living with HIV. AIDS 2009;23(Suppl 1):S123 -30.

5. Reynolds HW, Janowitz B, Wilcher R, Cates W. Contraception to prevent HIV-positive births: current contribution and potential cost savings in PEPFAR countries. Sexually transmitted infections. 2008; 84 Suppl 2:ii49- 53. doi:10.1136/sti.2008.030049 PMID: 18799493

6. Leslie J, Munyambanza E, Adamchak S, Grey T, Kirota K. Without Strong Integration of Family Planning into PMTCT Services Clients Remain with a High Unmet Need for Effective Family Planning. Inter-national Conference on Family Planning: Research and Best Practices. Kampala, Uganda2009.

7. Nakakeeto $\mathrm{ON}$, Umaranayake L. The global strategy to eliminate HIV infection in infants and young children: a seven-country assessment of costs and feasibility. AIDS. 2009; 23:987-95. PMID: 19425224

8. Petruney T, Harlan SV, Lanham M, Robinson ET. Increasing support for contraception as HIV prevention: stakeholder mapping to identify influential individuals and their perceptions. PLoS One. 2010; 5:e10781. doi: 10.1371/journal.pone.0010781 PMID: 20520728

9. Millennium Development Goal Indicators website: http://millennium indicators.un.org/

10. United Nations Department of Economic and Social Affairs (2011) World Contraceptive Use 2011. Available: http://www.un.org/esa/population/ publications /contraceptive2011/ wallchart_front.pdf. 
Accessed 2017 December 24.

11. The DHS Programme. “Unm et Need f or Family Planning.” Available at: http:/ / dhs program. com/ topics/ Unmet- Need. cfm.

12. Central Statistical Agency (CSA) [Ethiopia] and ICF. 2016. Ethiopia Demographic and Health Survey 2016. Addis Ababa, Ethiopia, and Roc kville, Maryland, USA: CSA and IC F.

13. Taulo F, Berry M, Tsui A, Makanani B, Kafulafula G, et al. Fertility intentions of HIV-1 infected and uninfected women in Malawi: a longitudinal study. AIDS Behav. 2009;13(1):20-7.

14. Bankole A, Biddlecom AE, Dzekedzeke K. Women's and Men's Fertility Preferences and Contraceptive Behaviors by HIV Status in 10 Sub-Saharan African Countries. AIDS Educ Prev. 2011;23(4):313 - 28.

15. Joint United Nations Programme on HIV/AIDS. UNAIDS World AIDS Day Report UNAIDS 2011

16. Habte D, Namasasu J. Family planning use among women living with HIV: knowing HIV positive status helps-results from a national survey. Reproductive health. 2015 Dec;12(1):41.

17. Keogh SC, Urassa M, Kumogola Y, Mngara J, Zaba B. Reproductive behaviour and HIV status of antenatal clients in northern Tanzania: opportunities for family planning and preventing mother-tochild transmission integration. Aids. 2009 Nov 1;23:S27-35.

18. Laryea DO, Amoako YA, Spangenberg K, Frimpong E, Kyei-Ansong J. Contraceptive use and unmet need for family planning among HIV positive women on antiretroviral therapy in Kumasi, Ghana. BMC women's health. $2014 \mathrm{Dec} ; 14(1): 126$.

19. Wekesa E, Coast E. Contraceptive need and use among individuals with HIV/AIDS living in the slums of Nairobi, Kenya. International Journal of Gynecology \& Obstetrics. 2015 Aug;130:E31-6.

20. Wanyenze RK, Matovu JK, Kamya MR, Tumwesigye NM, Nannyonga M, Wagner GJ. Fertility desires and unmet need for family planning among HIV infected individuals in two HIV clinics with differing models of family planning service delivery. BMC women's health. 2015 Dec;15(1):5.

21. Habte D, Namasasu J. Family planning use among women living with HIV: knowing HIV positive status helps-results from a national survey. Reproductive health. 2015 Dec;12(1):41.

22. Oyebode T, Sagay A, Musa J, Ekwempu C, Agaba P, Idoko J, Okonkwo P, Kanki P. Unmet need for contraception among human immunodeficiency virus-positive women in Jos, Nigeria: a call to integrate family planning and human immunodeficiency virus services. Journal of HIV and Human Reproduction. 2016 Jan 1;4(1):13.

23. Feyissa TR, Melka AS. Demand for modern family planning among married women living with HIV in western Ethiopia. PloS one. 2014 Nov 12;9(11):e113008.

24. Feyssa MD, Tsehay YB, Tadesse AW. Unmet Need for Family Planning Among Women in HIV. AIDS Care at Antiretroviral Treatment Clinic in South Ethiopia: A Challenge to Prevention of Mother to Child Transmission. J AIDS Clin Res. 2015;6(469):2.

25. Abeje G, Motbaynor A. Demand for family planning among HIV positive women on ART: the case of South Gondar and North Wollo Zones Amhara region. BMC research notes. 2016 Dec;9(1):43. 
26. Tadele A, Abebaw D, Ali R. Predictors of unmet need for family planning among all women of reproductive age in Ethiopia. Contraception and reproductive medicine. 2019 Dec;4(1):6.

27. Gurmu S, Tesfu S. Illness and choice of treatment in urban and rural Ethiopia. Ethiopian Journal of Economics. 2011;20(2):29-62.

28. Woldemichael A, Takian A, Akbari Sari A, Olyaeemanesh A. Availability and inequality in accessibility of health centre-based primary healthcare in Ethiopia. PloS one. 2019;14(3):e0213896.

29. Ayele W, Tesfaye H. Trends and determinants of unmet need for family planning and Programme options, Ethiopia: further analysis of the 2000, 2005, and 2011 demographic and health surveys. ICF International; 2013.

30. Hope R, Kendall T, Langer A, Bärnighausen T. Health systems integration of sexual and reproductive health and HIV services in sub-Saharan Africa: a scoping study. Journal of acquired immune deficiency syndromes (1999). 2014 Dec 1;67(Suppl 4):S259.

\section{Table 1}

Table 1: Socio-demographic characteristics of HIV positive women on ART at Gondar city public ART clinics, Northwest Ethiopia ( $\mathrm{N}=505), 2018$ 


\begin{tabular}{|c|c|c|c|}
\hline \multicolumn{2}{|l|}{ Variable } & \multirow{2}{*}{$\begin{array}{l}\text { Frequency } \\
257\end{array}$} & \multirow{2}{*}{$\begin{array}{l}\text { Percent } \\
58.3\end{array}$} \\
\hline Residence & Urban & & \\
\hline & Rural & 184 & 41.7 \\
\hline \multirow[t]{5}{*}{ Age } & $19-24$ & 23 & 5.2 \\
\hline & $25-29$ & 72 & 16.3 \\
\hline & $30-34$ & 125 & 28.3 \\
\hline & $35-39$ & 162 & 36.7 \\
\hline & Above 40 & 59 & 13.4 \\
\hline \multirow[t]{5}{*}{ Marital status } & Married & 247 & 56.0 \\
\hline & Single & 27 & 6.1 \\
\hline & Divorced & 115 & 26.1 \\
\hline & Widowed & 48 & 10.9 \\
\hline & Separated & 4 & 0.9 \\
\hline \multirow[t]{3}{*}{ Religion } & Orthodox & 404 & 91.6 \\
\hline & Muslim & 34 & 7.7 \\
\hline & Catholic & 3 & .7 \\
\hline \multirow[t]{4}{*}{ Ethnicity } & Amhara & 430 & 97.5 \\
\hline & Oromo & 2 & 0.5 \\
\hline & Tigray & 2 & 0.5 \\
\hline & Kimant & 7 & 1.6 \\
\hline \multirow[t]{5}{*}{ Educational status } & Illiterate & 139 & 31.5 \\
\hline & Able to read and write & 62 & 14.1 \\
\hline & Completed Primary Education & 115 & 26.1 \\
\hline & Completed Secondary Education & 77 & 17.5 \\
\hline & College Diploma and above & 48 & 10.9 \\
\hline \multirow[t]{6}{*}{ Occupational status } & Merchant & 95 & 21.5 \\
\hline & Government employ & 64 & 14.5 \\
\hline & Housewife & 144 & 32.7 \\
\hline & Daily laborer & 127 & 28.8 \\
\hline & Others & 11 & 2.5 \\
\hline & Farmer & 7 & 1.6 \\
\hline \multirow[t]{4}{*}{ Income } & Less than 850 ETB & 110 & 24.9 \\
\hline & $850-1005$ ЕTВ & 111 & 25.2 \\
\hline & 1006-2158.5 ЕTB & 110 & 24.9 \\
\hline & Above 2159 ETB & 110 & 24.9 \\
\hline
\end{tabular}

\section{Supplementary Files}


This is a list of supplementary files associated with this preprint. Click to download.

- supplement1.pdf 